Archived version from NCDOCKS Institutional Repository http://libres.uncg.edu/ir/asu/

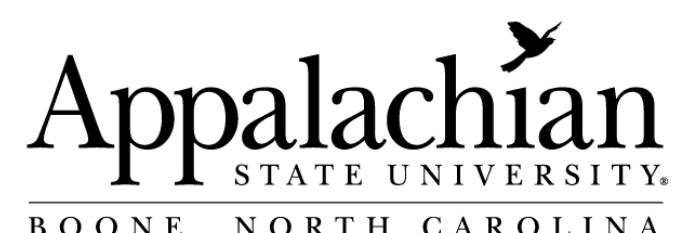

B O O NE, NORTH CAROLINA

\title{
Costs of Diarrheal Disease and the Cost-Effectiveness of a Rotavirus Vaccination Program in Kyrgyzstan
}

\author{
By: Richard D. Rheingans, Elmira T. Flem, Renat Latipov, Zuridin S. \\ Nurmatov, Yiting Xue and Kaliya T. Kasymbekova,
}

\begin{abstract}
Introduction. We examined the cost-effectiveness of a rotavirus immunization program in Kyrgyzstan, a country eligible for vaccine funding from the GAVI Alliance.

Methods. We estimated the burden of rotavirus disease and its economic consequences by using national and international data. A cost-effectiveness analysis was conducted from government and societal perspectives, along with a range of 1-way sensitivity analyses.

Results. Rotavirus-related hospitalizations and outpatient visits cost US $\$ 580,864$ annually, of which $\$ 421,658$ (73\%) is direct medical costs and \$159,206 (27\%) is nonmedical and indirect costs. With $95 \%$ coverage, vaccination could prevent $75 \%$ of rotavirus-related hospitalizations and deaths and $56 \%$ of outpatient visits and could avert $\$ 386,193$ (66\%) in total costs annually. The medical break-even price at which averted direct medical costs equal vaccination costs is $\$ 0.65 /$ dose; the societal break-even price is $\$ 1.14 /$ dose for a 2 -dose regimen. At the current GAVI Alliance-subsidized vaccine price of $\$ 0.60 /$ course, rotavirus vaccination is cost-saving for the government.

Vaccination is cost-effective at a vaccine price $\$ 9.41 /$ dose, according to the costeffectiveness standard set by the 2002 World Health Report.

Conclusions. Addition of rotavirus vaccines to childhood immunization in Kyrgyzstan could substantially reduce disease burden and associated costs. Vaccination would be cost-effective from the national perspective at a vaccine price $\$ 9.41$ per dose
\end{abstract}

Richard D. Rheingans, Elmira T. Flem, Renat Latipov, Zuridin S. Nurmatov, Yiting Xue and Kaliya T. Kasymbekova (2009) "Costs of Diarrheal Disease and the Cost-Effectiveness of a Rotavirus Vaccination Program in Kyrgyzstan" Journal of infectious diseases issue 200 pp.S195-S202 
Rotaviruses are the most common cause of severe diarrhea in young children, leading to an estimated 527,000 deaths annually, of which $85 \%$ occur in developing countries [1]. The GAVI Alliance (formerly known as the Global Alliance for Vaccines and Immunization) currently provides 2 new rotavirus vaccines at a reduced price to eligible low-income countries in Europe and Latin America to help advance their introduction into immunization programs [2]. The decision to commit resources to a given health care intervention should be based on evaluation of costs of the intervention and its effect on disease; this is performed through cost-effectiveness analyses. Most economic evaluations of rotavirus immunization have been done in industrialized countries [3-6], whereas little research on the cost-effectiveness of new rotavirus vaccines in low-income countries is available [7-9], particularly GAVI Alliance-eligible countries. Moreover, the available economic analyses of rotavirus immunization programs used a wide range of methods, which makes comparison across countries and regions challenging [10]. 
To inform policy makers in resource-limited settings about the costs and benefits of using rotavirus vaccines, we conducted a cost-effectiveness analysis of rotavirus vaccination in Uzbekistan, a GAVI Alliance-eligible country; this was done before the GAVI Alliance-subsidized price of the vaccine was known to the government [11]. Uzbekistan is a member of the European region of the World Health Organization (WHO), which covers other countries of the Commonwealth of Independent States, including 4 Central Asian countries. The Commonwealth of Independent States region is highly diverse, and economic indicators and levels of morbidity and mortality in childhood vary substantially among countries, even inside Central Asia [12]. Evidence on cost-effectiveness from a single study, therefore, is insufficient to draw conclusions for other parts of the region. Recognizing regional diversity and specific features of GAVI Alliance-eligible countries, we sought to further explore the disease costs and benefits of rotavirus immunization and selected Kyrgyzstan as a case for this analysis. By choosing another GAVI Alliance-eligible country, we aimed to provide data that would be applicable to other GAVI Alliance-eligible countries in the region.

Kyrgyzstan has a gross domestic product of US $\$ 490$ per capita [12], and its state-owned health care system provides services to 5.1 million inhabitants. In addition to the state budget, the Kyrgyz health care sector receives funds from insurance, private out-of-pocket payments, and international grants $[13,14]$. The government currently finances only $40 \%$ of all vaccines in the national program [12], but routine childhood vaccinations are free. Coverage for routine vaccines is high (92\%-99\%) [15], with the lowest coverage for vaccination against hepatitis $\mathrm{B}$ virus $(90 \%)$. On the basis of data from sentinel hospital surveillance for rotavirus, $26 \%$ (95\% confidence interval [CI], $24 \%-27 \%$ ) of all hospitalizations due to diarrhea among children aged $<5$ years in Kyrgyzstan are attributable to rotavirus (authors' unpublished data).

The economic analyses presented here aimed to estimate health care and societal costs of rotavirus disease and to determine whether vaccination would be a good investment with respect to health care and costs. Analyses were conducted from the national perspective, when costs incurred only by the government health care sector were considered, and from a broader societal perspective, when all costs were included.

\section{METHODS}

The study was approved by the Kyrgyz National Ethics Committee and by the Regional Ethics Committee for Medical Research, Oslo, Norway. Study methods were similar to methods used in the Uzbekistan cost-effectiveness analysis [11], to ensure comparability of results.

Health care and societal costs. To estimate the economic burden of rotavirus disease, we combined the numbers of ex- pected rotavirus-associated events (hospitalizations and outpatient visits) with the estimates of health care costs for these events. To estimate costs of rotavirus-related hospitalizations, we followed WHO guidelines for estimation of the economic burden of diarrheal disease [16]. We collected data from a sample of 180 children aged $<5$ years who were hospitalized with acute diarrhea in the Republican Hospital of Infectious Diseases in Bishkek, Kyrgyzstan, and the Children's Hospital in Osh, Kyrgyzstan. These hospitals implemented rotavirus surveillance in 2005 and were selected because they represent common public hospitals that provide inpatient care for children with diarrhea. No private inpatient facilities are available to treat patients with infectious diarrhea. Children hospitalized with diarrhea were enrolled prospectively from 9 February through 28 April 2008 after written informed consent was obtained from a parent or legal guardian. Costs of treating patients with any type of diarrhea were assumed to be similar to costs of treating patients with rotavirus diarrhea.

Data on the use of hospital resources were extracted from medical charts and included duration of hospitalization, number and type of diagnostic tests, and quantity of medications and supplies used during hospitalization. Unit costs of drugs, diagnostic tests, and bed days were obtained from hospital records and were combined with data on the use of hospital resources, to estimate direct medical costs. Children aged $<5$ years are exempt from copayments for inpatient care, but informal payments to hospital staff remain common. Parents offer in-kind or cash payments to ensure better care for their child. These out-of-pocket payments were included in direct medical costs because our analysis was conducted from societal and government perspectives. We used the mean duration of rotavirus-associated hospitalization (5.6 days), which is based on surveillance data, to ensure that estimates of hospital per diem costs were applicable to rotavirus gastroenteritis. Costs of transportation before hospitalization and during the hospital stay and costs of self-provision of food for caregivers staying in the hospital together with ill children were combined to estimate nonmedical costs. Indirect costs were calculated using the time lost from paid work by all caregivers as a result of the child's illness and the monthly household income. We collected information on nonmedical and indirect costs by interviewing caregivers with a questionnaire given at hospital discharge. Costs were collected in local currency and were converted to US dollars by using the exchange rate for February 2008 [17].

It was not feasible to collect detailed data on costs of outpatient visits. We therefore used an estimate of the unit cost of an outpatient visit in Kyrgyzstan based on the Choosing Interventions that are Cost Effective (CHOICE) estimate provided by the WHO in 2000 [18]. The CHOICE estimate in international dollars was first converted to local currency, was adjusted for inflation [19], and then was converted to 2008 US 
dollars [17]. The CHOICE estimate excluded costs of drugs and diagnostics. These costs were estimated using data on children with diarrhea who sought care in outpatient clinics before hospitalization and whose families covered the costs of drugs and diagnostics in a form of out-of-pocket expenses. These costs were added to the CHOICE estimate to derive a total cost per outpatient visit. Costs of episodes of mild rotavirus disease among children who received home care and costs of potential adverse events associated with vaccination were not included.

Model design and vaccination strategy. We used a spreadsheet model to estimate rotavirus disease burden and associated costs that would occur with and without vaccination for the 2006 birth cohort $(n=116,000)$ followed up for the first 5 years of life. A full description of the model is available elsewhere [9]. Annual numbers of rotavirus deaths, hospitalizations, and outpatient visits were estimated using hospital surveillance data, national gastroenteritis statistics, and international estimates of mortality for children aged $<5$ years. We modeled on-time immunization with a 2-dose vaccine at ages 2 months and 4 months and assumed an efficacy against rotavirus hospitalizations and deaths of $85 \%$ (95\% CI, 69.6\%93.5\%) [20] and an efficacy against outpatient visits of $63 \%$ (range, 56\%-70\%), on the basis of clinical trails [21] and our own assumptions. We applied vaccine coverage of $95 \%$, on the basis of current coverage of diphtheria-tetanus toxoid-pertussis vaccine [15]. We used vaccine prices of $\$ 0.30-\$ 20 /$ course. This included prices at which rotavirus vaccines are currently available to Kyrgyzstan from the GAVI Alliance: $\$ 0.60 /$ course if rotavirus vaccine is introduced as a first new vaccine or $\$ 0.30$ / course if it is introduced as a second new vaccine [2]. Costs of the vaccination program included the cost of vaccine doses needed for the birth cohort based on vaccine coverage, $10 \%$ of loss from waste, and $\$ 0.50$ administration cost per dose; these costs were based on published estimates $[8,9]$.

Cost-effectiveness analysis. As a measure of cost-effectiveness, we computed an incremental cost-effectiveness ratio (ICER) for all vaccine prices and expressed the ICER as cost per disability-adjusted life-year (DALY). The DALY loss from mortality and all symptomatic cases was calculated using published methods [11]. The ICER was the net cost of administration of rotavirus vaccination minus the medical costs averted by vaccination, divided by the DALYs or deaths averted by vaccination. Costs and benefits were discounted to the present value by using an annual discount rate of $3 \%$. To determine whether vaccination was cost-effective, we applied the costeffectiveness standard of the World Health Report, which suggested that interventions with a cost per DALY less than the per capita gross domestic product are very cost-effective [22]. To test the robustness of model results, we performed a range of 1-way sensitivity analyses by varying 1 parameter at a time and holding all other parameters at their base-case values. Rates of rotavirus-associated events and estimates of vaccine efficacy, coverage, price, administration costs, disease costs, and discount rates were varied within $\pm 25 \%$ or $\pm 50 \%$ of the basecase value or with use of ranges from our own data or published data.

\section{RESULTS}

Health care and societal costs. We enrolled 180 children aged $<5$ years who were hospitalized with diarrhea. We excluded 5 children because they stayed in the hospital for $>14$ days (range, 15-20 days); the costs of treating these cases would not be representative of the costs of treating routine rotavirus cases. Of 175 recruited children, 93 (53\%) were hospitalized in Bishkek and $82(47 \%)$ were hospitalized in Osh (Table 1). Of the 175 children, 137 (78\%) sought care before hospital admission, and almost one-half of patients used an outpatient clinic; the rest sought other points of care. The median distance from the hospital to a patient's home was $5 \mathrm{~km}$ (range, 1-200 km), and $95 \%$ of families used transportation to reach the hospital. Families of children with diarrhea predominantly used savings (62\%) or had to reduce household expenses (31\%) to generate funds to cover the costs associated with illness. The mean cost of rotavirus-related hospitalization to the government was estimated to be $\$ 39$. The total average cost to society per hospitalized case was calculated to be $\$ 87$ (range, $\$ 25-\$ 666$ ). Medical costs accounted for $52 \%$ of the total, and nonmedical and indirect costs accounted for $48 \%$ (Table 2). Of the direct medical costs, $88 \%$ were incurred by the health care system, but households covered $12 \%$ of all medical costs by purchasing additional drugs and by providing informal payments to hospital staff. Indirect costs were $\$ 2.50$ per child because only $10 \%$ of parents reported losing time from paid work as a result of the child's illness.

The unit cost of an outpatient visit, excluding the costs of drugs and diagnostics, was $\$ 2.04$, on the basis of CHOICE data [18]. We assumed that the total cost of a rotavirus-associated outpatient visit was $\$ 8.24$ per child, because $47 \%$ of surveyed children with diarrhea sought care at an outpatient clinic before hospitalization and because their families paid out-of-pocket a mean of $\$ 6.20$ for drugs and diagnostics. This value may overestimate the costs of treating outpatient diarrhea cases, because hospitalized cases that were originally outpatient cases are more severe, but it includes relevant treatment costs and therefore provides a more comprehensive picture than the unit cost alone.

Cost-effectiveness analysis. We obtained base-case values and sensitivity ranges of input parameters to populate the model, using available data and published research (Table 3). We estimated that 3895 hospitalizations, 31,160 outpatient visits, and 174 deaths among children aged $<5$ years (Table 4 ) were attributable to rotavirus each year. The total national cost 
Table 1. Prehospitalization History of Children Aged $<5$ Years with Diarrhea and Characteristics of Households of Patients with Diarrhea in Bishkek and Osh, Kyrgyzstan, 2008

\begin{tabular}{|c|c|c|c|}
\hline Characteristic & $\begin{array}{l}\text { Bishkek } \\
(n=93)\end{array}$ & $\begin{array}{c}\text { Osh } \\
(n=82)\end{array}$ & $\begin{array}{c}\text { Total } \\
(n=175)\end{array}$ \\
\hline \multicolumn{4}{|l|}{ Type of care before admission } \\
\hline Public outpatient clinic & $50(53.8)$ & $32(39.0)$ & $82(46.9)$ \\
\hline Pharmacy & $9(9.7)$ & $23(28.0)$ & $32(18.3)$ \\
\hline Hospital & $13(14.0)$ & $4(4.9)$ & $17(9.7)$ \\
\hline Private clinic & $1(1.1)$ & $4(4.9)$ & $5(2.9)$ \\
\hline Traditional healer & $0(0)$ & $1(1.2)$ & $1(0.6)$ \\
\hline No care & $20(21.5)$ & $18(22.0)$ & $38(21.7)$ \\
\hline \multicolumn{4}{|l|}{ Type of transportation to hospital } \\
\hline Personal car & $23(24.7)$ & $39(47.6)$ & $62(35.4)$ \\
\hline Ambulance & $30(32.3)$ & $17(20.7)$ & 47 (26.9) \\
\hline Taxi & $32(34.4)$ & $10(12.2)$ & $42(24.0)$ \\
\hline Public transportation & $8(8.6)$ & $8(9.8)$ & $16(9.1)$ \\
\hline Foot & $0(0)$ & $8(9.8)$ & $8(4.6)$ \\
\hline Distance to hospital, median km (range) & $5(1-200)$ & $3.5(1-70)$ & $5(1-200)$ \\
\hline Monthly household income, mean dollars \pm SD & $223 \pm 297.6$ & $310 \pm 245.1$ & $264 \pm 276.9$ \\
\hline Children per household, median no. (range) & $1(1-4)$ & $2(1-8)$ & $2(1-8)$ \\
\hline Adults per household, median no. (range) & $2(1-8)$ & $3(1-12)$ & $2(1-12)$ \\
\hline \multicolumn{4}{|l|}{ Sources of funds } \\
\hline Savings & $56(61.5)$ & $52(63.4)$ & $108(61.7)$ \\
\hline Reduction in other expenses & $29(31.2)$ & $26(31.7)$ & 55 (31.4) \\
\hline Loan from relatives or friends & $6(6.6)$ & $4(4.9)$ & $10(5.7)$ \\
\hline
\end{tabular}

NOTE. Data are no. (\%) of children, unless otherwise indicated. SD, standard deviation.

of rotavirus disease amounts to $\$ 580,864 /$ year $(\$ 5.01 /$ child/ year), of which $\$ 421,658 /$ year $(73 \%)$, or $\$ 3.63 /$ child/year, is direct medical costs. If vaccine is delivered on schedule, vaccination could avert annually $75 \%$ of hospitalizations and deaths and $56 \%$ of outpatient visits, resulting in reductions of $63 \%$ in direct medical costs and $66 \%$ in total costs. If vaccine is introduced at the current GAVI Alliance-subsidized price of $\$ 0.60 /$ child, the annual cost of the vaccine alone would be $\$ 72,732$, and the costs of administration of the immunization program would be $\$ 110,200 /$ year, resulting in a total cost of $\$ 182,932 /$ year. The program cost increases with higher vaccine prices; at a price of $\$ 2 /$ child, the program cost is estimated to be $\$ 352,640$, and an expenditure of $\$ 85,621$ in net medical costs will be required for vaccination.

The direct medical break-even price at which averted medical costs equal intervention costs is $\$ 0.65 /$ dose for a 2 -dose regimen. Therefore, introduction of rotavirus vaccines into the immunization program at current GAVI Alliance-subsidized prices of $\$ 0.30 /$ course and $\$ 0.60 /$ course will generate cost savings from the government perspective (Table 5). Inclusion of nonmedical and indirect costs results in the societal break-even price of $\$ 1.14 /$ dose. Vaccination could be cost-saving with vaccine prices in the range of $\$ 1-\$ 2 /$ course from the societal perspective. An increase in the vaccine price would require net financial investment by the government, but the price per vaccine dose could be as high as $\$ 9.41$, and vaccination would still be cost-effective from the government perspective, according to the cost-effectiveness standard of the World Health Report [22].

Sensitivity analyses. The cost-effectiveness of the program was most sensitive to changes in rates of rotavirus-associated mortality, estimates of vaccine efficacy against mortality, and vaccine price (Table 6). For example, decreasing the baseline mortality of 1.5 deaths per 1000 persons by $25 \%$ resulted in an increase in the ICER of 33\%, compared with the base-case value (218 vs. 290 ), whereas increasing the mortality by $25 \%$ resulted in a decrease in the ICER by $20 \%$, compared with the base-case value (218 vs. 174). The cost-effectiveness of the program was most sensitive to changes in the vaccine price; prices of $\$ 5 /$ course and $\$ 15 /$ course resulted in ICER values of $\$ 78$ / DALY and \$357/DALY, respectively, corresponding to a change in the ICER of $64 \%$. Varying the vaccine efficacy against mortality had a greater effect on the cost-effectiveness than did varying the efficacy against hospitalization; adjustment of the efficacy against mortality to $69.6 \%$ increased the ICER by $22 \%$, compared with the base-case value, whereas $69.6 \%$ efficacy against hospitalization increased the ICER by only $5 \%$. Variability in rates of rotavirus-associated outpatient visits, hospi- 
Table 2. Hospitalization Costs per Case of Diarrhea Incurred by the Health Care System and Households, Kyrgyzstan, 2008

\begin{tabular}{|c|c|c|c|}
\hline \multirow[b]{2}{*}{ Cost category } & \multicolumn{3}{|c|}{ Cost per hospitalized case, 2008 US dollars } \\
\hline & $\begin{array}{c}\text { Health care } \\
\text { system }\end{array}$ & Household & Total (range) \\
\hline \multicolumn{4}{|l|}{ Direct medical } \\
\hline Expenses before hospitalization ${ }^{a}$ & 0 & 4.6 & $4.6(0-123.8)$ \\
\hline Diagnostics & 4.8 & 0 & $4.8(1.3-13.4)$ \\
\hline Drugs & 7.8 & 0.5 & $8.3(0-44.2)$ \\
\hline Bed days $^{b}$ & 26.4 & 0 & $26.4(23.6-29.2)$ \\
\hline Informal payments ${ }^{c}$ & 0 & 0.9 & $0.9(0-11.0)$ \\
\hline \multicolumn{4}{|l|}{ Direct nonmedical } \\
\hline Transportation & 0 & 14.5 & $14.5(0-236.7)$ \\
\hline Self-provision of food & 0 & 24.9 & $24.9(0-165.1)$ \\
\hline Indirect costs & 0 & 2.5 & $2.5(0-43.1)$ \\
\hline Total costs & 39.0 & 47.9 & $86.9(24.9-666.5)$ \\
\hline
\end{tabular}

a Out-of-pocket payments for drugs, diagnostics, and/or consultation fees before hospitalization for all surveyed patients except for those that sought care at a polyclinic.

b Adjusted for a mean length of hospitalization of 5.6 days for rotavirus-positive patients, as determined from hospital rotavirus surveillance data.

${ }^{\mathrm{c}}$ Informal payments to hospital care providers who are outside official payment channels.

talization and outpatient costs, and vaccine administration costs had a limited effect on the cost-effectiveness of the program. Decreasing the vaccine coverage to $71 \%$ did not affect the costeffectiveness, and using a higher discount rate of $6 \%$ resulted in a change in the ICER of only $1 \%$.

\section{DISCUSSION AND CONCLUSIONS}

This study quantified the economic burden of rotavirus disease and examined the costs and benefits of the addition of new rotavirus vaccines to routine childhood immunization in a
GAVI Alliance-eligible country inside the European region of the WHO. The national burden of rotavirus disease in Kyrgyzstan results in a total annual cost of US\$580,864, of which $\$ 421,658$ (73\%), or $\$ 3.63 /$ child/year, is direct medical costs. Total health care expenditure of the country in 2004 was estimated to be $\$ 102$ per capita, with the government share constituting $41 \%$ and private-out-of-pocket payments accounting for $51 \%$ [14]. Therefore, the medical costs of rotavirus disease represent $3.5 \%$ of total health care expenditure, demonstrating a substantial economic effect of rotavirus on the health care

Table 3. Base-Case Values and Sensitivity Ranges of Input Parameters in the Rotavirus Vaccine Cost-Effectiveness Model, Kyrgyzstan, 2008

\begin{tabular}{|c|c|c|c|}
\hline Parameter & Base-case value & Sensitivity range $\mathrm{a}^{\mathrm{a}}$ & Source(s) \\
\hline \multicolumn{4}{|c|}{ Rotavirus burden, rate per 1000 persons } \\
\hline Mortality & 1.5 & $\pm 25 \%$ & [12], authors' data \\
\hline Hospitalization & 33.6 & $\pm 25 \%$ & Authors' data \\
\hline Outpatient visit & 269 & $\pm 25 \%$ & Authors' data \\
\hline \multicolumn{4}{|l|}{ Vaccine efficacy, ${ }^{\mathrm{b}} \%$} \\
\hline Against hospitalization and death & 85 & $69.9-93.5$ & [20] \\
\hline Against outpatient visit & 63 & $56-70$ & [21], assumption \\
\hline Vaccine coverage, $\%$ & 95 & $-25 \%$ and $+4 \%$ & [15] \\
\hline Hospitalization costs & $\$ 86.9$ & $\pm 25 \%$ & Authors' data \\
\hline Outpatient visit costs & $\$ 8.2$ & $\pm 25 \%$ & [18], authors' data \\
\hline Vaccine price per child & $\$ 0.60$ & $\$ 0.30-\$ 20$ & [2], assumption \\
\hline Administration cost per child & $\$ 0.50$ & $\$ 0.25-\$ 1.00$ & {$[8,9]$, assumption } \\
\hline Discount rate, \% & 3 & $0-6$ & [9] \\
\hline
\end{tabular}

a Percentage of base-case value or $95 \%$ confidence interval is used for sensitivity ranges.

b Efficacy of a 2 dose-regimen, under the assumption of on-time administration. 
Table 4. Estimates of Health and Economic Burden of Rotavirus under the BaseCase Parameter Values, Kyrgyzstan, 2008

\begin{tabular}{lrrrr}
\hline Variable & $\begin{array}{c}\text { Without } \\
\text { vaccination }\end{array}$ & $\begin{array}{c}\text { With } \\
\text { vaccination }\end{array}$ & $\begin{array}{c}\text { Averted by } \\
\text { vaccination }\end{array}$ & Decrease, \% \\
\hline $\begin{array}{l}\text { No. of rotavirus events } \\
\text { Deaths }\end{array}$ & 174 & 44 & 131 & 75 \\
Hospitalizations & 3895 & 978 & 2917 & 75 \\
Outpatient visits & 31,160 & 13,862 & 17,299 & 56 \\
Annual costs, \$ & & & & \\
Medical & 421,658 & 154,630 & 267,028 & 63 \\
Nonmedical & 149,734 & 37,659 & 112,075 & 75 \\
Indirect & 9472 & 2382 & 7090 & 75 \\
\multicolumn{1}{c}{ Total } & 580,864 & 194,671 & 386,193 & 66 \\
\hline
\end{tabular}

sector and households. Given the estimates of vaccine efficacy and vaccine coverage used in the analysis, vaccination could reduce rotavirus deaths and hospitalizations among children aged $<5$ years by $75 \%$, reduce outpatient visits by $56 \%$, and avert $66 \%$ of the total costs.

With the current GAVI Alliance-subsidized vaccine prices of $\$ 0.30-\$ 0.60$ /course [2], the cost of vaccine needed to immunize the national birth cohort would be $\$ 36,366-\$ 72,732$, but an additional $\$ 110,200$ is estimated for administration costs. Introduction of rotavirus vaccines at current GAVI Alliance-subsidized prices would save costs for the government, because Kyrgyzstan could receive a "one-off" grant of $\$ 100,000$ from the GAVI Alliance to support administration costs of a new vaccine [2]. Countries will probably pay a higher price for vaccines in the future because GAVI Alliance funding is temporally limited; moreover, because grants may not fully cover additional costs of administration of a new vaccine, rotavirus vaccination may not result in cost savings and will require net expenditure by the government. However, if the price per vaccine dose were as high as $\$ 9.41$, vaccination would remain costeffective from the government perspective.

We could directly compare the results of this study only with those of our previous cost-effectiveness analysis in Uzbekistan [11], because of the lack of economic evaluations of rotavirus disease in GAVI Alliance-eligible countries. If cost estimates from the study in Uzbekistan are inflated to 2008 US dollars, the mean cost of rotavirus hospitalization equates to $\$ 95$ per child, compared with the estimate of $\$ 87$ in the present study. Direct medical and nonmedical costs in Kyrgyzstan contributed almost equally to the total cost of rotavirus hospitalizations (52\% and $45 \%$, respectively), whereas in Uzbekistan, medical costs accounted for the largest percentage (89\%) of the total cost, compared with nonmedical costs (10.5\%). Indirect costs in both countries were low because most caregivers were unemployed women or female siblings, so very few people lost time from paid work. High nonmedical costs in Kyrgyzstan are attributed to higher costs of transportation and self-provision of food for caregivers staying in the hospital with ill children. If all out-of-pocket payments of Kyrgyz families are considered together, they account for $54 \%$ of the total costs of hospitalizations and outpatient visits, thus representing a major source of financing of health care services for rotavirus cases. These family-borne costs constitute $30 \%$ of the mean monthly household income, a finding similar to that in Uzbekistan, where out-of-pocket expenses in 2004 were $~ 37 \%$ of mean monthly household income. Savings, reduction in other expenses, and private loans were used similarly by households in these 2 countries to cover costs incurred during illness. Because private outof-pocket expenses have been shown to considerably reduce access to health care in Central Asia [13] (particularly for poor persons), reduction in these costs could be important in reducing inequalities in health care

Our analysis in Uzbekistan [11] demonstrated that rotavirus vaccination could reduce disease burden by $91 \%$ and be cost-

\section{Table 5. Expected Costs and Benefits of Rotavirus Vaccination} in Kyrgyzstan

\begin{tabular}{lccc}
\hline & & \multicolumn{2}{c}{$\begin{array}{c}\text { Incremental cost- } \\
\text { effectiveness } \\
\text { ratio per DALY, \$ }\end{array}$} \\
\cline { 2 - 4 } $\begin{array}{l}\text { Vaccine price, } \\
\text { \$course }\end{array}$ & $\begin{array}{c}\text { Program } \\
\text { cost, }^{2} \$\end{array}$ & $\begin{array}{l}\text { Government } \\
\text { perspective }\end{array}$ & $\begin{array}{c}\text { Societal } \\
\text { perspective }\end{array}$ \\
\hline 0.30 & 146,566 & CS & CS \\
0.60 & 182,932 & CS & CS \\
1.00 & 231,420 & CS & CS \\
2.00 & 352,640 & 20 & CS \\
3.00 & 473,860 & 48 & 22 \\
5.00 & 716,300 & 104 & 78 \\
7.00 & 958,740 & 160 & 134 \\
10.00 & $1,322,400$ & 243 & 218 \\
\hline
\end{tabular}

NOTE. CS, cost-saving; DALY, disability-adjusted life-year.

${ }^{a}$ Program cost includes cost of vaccine doses for the national birth cohort ( $n=116,000)$ based on vaccine coverage, $10 \%$ of vaccine waste, and administration cost of $\$ 0.50$ per child. 
Table 6. Effect of Variability in Key Input Parameters on the Incremental Cost-Effectiveness Ratio (ICER) of Rotavirus Vaccination, Kyrgyzstan

\begin{tabular}{|c|c|c|c|c|}
\hline Input parameter & $\begin{array}{l}\text { Parameter } \\
\text { value }\end{array}$ & $\begin{array}{c}\text { Change in } \\
\text { parameter value, }{ }^{a} \%\end{array}$ & $\begin{array}{l}\text { ICER per } \\
\text { DALY, \$ }\end{array}$ & $\begin{array}{l}\text { Change in } \\
\text { ICER, }^{\mathrm{a}} \%\end{array}$ \\
\hline \multicolumn{5}{|c|}{ Rotavirus mortality per 1000 persons } \\
\hline Low & 1.1 & -25 & 290 & +33 \\
\hline Base-case & 1.5 & $\ldots$ & 218 & $\ldots$ \\
\hline High & 1.9 & +25 & 174 & -20 \\
\hline \multicolumn{5}{|c|}{ Vaccine efficacy against mortality, \% } \\
\hline Low & 69.6 & -18 & 266 & +22 \\
\hline Base-case & 85.0 & $\ldots$ & 218 & $\ldots$ \\
\hline High & 93.5 & +10 & 198 & -9 \\
\hline \multicolumn{5}{|c|}{ Vaccine price/course, $\$$} \\
\hline Low & 5 & -50 & 78 & -64 \\
\hline Base-case & 10 & $\ldots$ & 218 & $\ldots$ \\
\hline High & 15 & +50 & 357 & +64 \\
\hline \multicolumn{5}{|c|}{ Vaccine administration costs per child, $\$$} \\
\hline Low & 0.25 & -50 & 205 & -6 \\
\hline Base-case & 0.50 & $\ldots$ & 218 & $\ldots$ \\
\hline High & 1.0 & +100 & 243 & +11 \\
\hline \multicolumn{5}{|c|}{ Hospitalization and outpatient costs, \$ } \\
\hline Low & 65.2 & -25 & 233 & +7 \\
\hline Base-case & 86.9 & $\ldots$ & 218 & $\ldots$ \\
\hline High & 108.6 & +25 & 202 & -7 \\
\hline
\end{tabular}

effective if the price of vaccine is $\$ \$ 25 /$ child, using international mortality estimates and under the assumption of a vaccine efficacy of $93 \%$ against hospitalization and death due to rotavirus. The similar results for cost-effectiveness are not surprising, because these countries have comparable income levels and rotavirus disease burden. These findings suggest that rotavirus vaccination in other GAVI Alliance-eligible countries, particularly in the same region, could also be cost-effective and perhaps cost-saving, depending on the vaccine price and the analysis perspective. Economic evaluations are very context specific, but cost-effectiveness evidence from these 2 studies is directly comparable and consistent, because we applied the same methods in both analyses. Our results are in agreement with other studies done in developing countries that demonstrated that rotavirus vaccination could be cost-effective if the vaccine cost is $\leqslant \$ 7.26 /$ dose in Vietnam [8] or $\$ 12.96 /$ course in low-income Asian countries [9].

The strength of our study is the use of consistent methods to facilitate comparison within the same region and income strata, but the present study has limitations. Our estimates may not be precise, because accurate calculation of disease costs is difficult. We tested the uncertainty of this parameter in the sensitivity analysis, but the overall economic effect of disease may have been over- or underestimated. Our cost estimates are not fully representative, because we calculated the cost of a hospital bed day on the basis of data from only 2 hospitals; for outpatient visits, the costs of diagnostics and drugs were derived from a sample of hospitalized patients with diarrhea who initially sought outpatient care. This could have been an overestimate, because it does not reflect costs of treating less severe outpatient cases that do not result in hospitalization. We did not include costs of treating nosocomial rotavirus cases or costs associated with mild episodes of disease among patients who do not seek health care. Neither did we consider costs of adverse events associated with rotavirus vaccination, because available data do not suggest an increased risk of such events [23]. The risk of possible adverse events and their costs should be considered in future analyses to obtain a more comprehensive picture of cost-effectiveness, because the safety of these vaccines in routine immunization has not been demonstrated.

Using a range of epidemiological, clinical, and economic parameters that are likely to be applicable to many GAVI Alliance-eligible countries, our analyses demonstrated that introduction of new rotavirus vaccines in routine childhood immunization in Central Asia would greatly reduce the burden of rotavirus disease and the related health care and societal costs. Rotavirus immunization at a cost of $\$ \$ 9.41$ per vaccine dose would be cost-effective from the national perspective, but 
the affordability of the program in the long-term is uncertain, given that government health care expenditure was $\sim \$ 42$ per capita in 2004 [14]. Competing priorities in health care (including the need for other vaccines not currently used in the national immunization program) will dictate resource allocation and will affect the decision of whether to invest in rotavirus vaccination.

\section{Acknowledgments}

We thank the Department of State Sanitary-Epidemiologic Surveillance and the Ministry of Health for their valuable contributions to the formal and organizational aspects of the study. We also thank the staff at the study hospitals, for their assistance during collection of data, and colleagues at the Norwegian Knowledge Center for Health Services, for useful discussions on modeling methods.

\section{References}

1. World Health Organization. Rotavirus vaccines. Wkly Epidemiol Rec 2007; 82:285-95.

2. Lob-Levyt J. Re: 2007 update on support to countries from the GAVI Alliance. Document GAVI/07/040/ir/hb. GAVI Alliance, March 2007. Available at: http://www.gavialliance.org/resources/GAVI_Letter_Update _Mar07.pdf. Accessed 22 February 2008.

3. Goossens LM, Standaert B, Hartwig N, Hovels AM, Al MJ. The costutility of rotavirus vaccination with Rotarix (RIX4414) in the Netherlands. Vaccine 2008; 26:1118-27.

4. Ho AM, Nelson EA, Walker DG. Rotavirus vaccination for Hong Kong children: an economic evaluation from the Hong Kong Government perspective. Arch Dis Child 2008; 93:52-8.

5. Jit M, Edmunds WJ. Evaluating rotavirus vaccination in England and Wales. Part II. The potential cost-effectiveness of vaccination. Vaccine 2007; 25:3971-9.

6. Lorgelly PK, Joshi D, Iturriza GM, Gray J, Mugford M. Exploring the cost effectiveness of an immunization programme for rotavirus gastroenteritis in the United Kingdom. Epidemiol Infect 2008; 136:44-55.

7. Ehrenkranz P, Lanata CF, Penny ME, Salazar-Lindo E, Glass RI. Rotavirus diarrhea disease burden in Peru: the need for a rotavirus vaccine and its potential cost savings. Rev Panam Salud Publica 2001; 10:240-8.

8. Fischer TK, Anh DD, Antil L, et al. Health care costs of diarrheal disease and estimates of the cost-effectiveness of rotavirus vaccination in Vietnam. J Infect Dis 2005; 192:1720-6.

9. Podewils LJ, Antil L, Hummelman E, Bresee J, Parashar UD, Rheingans R. Projected cost-effectiveness of rotavirus vaccination for children in Asia. J Infect Dis 2005; 192(Suppl 1):S133-45.
10. Walker DG, Rheingans R. Cost-effectiveness of rotavirus vaccines. Expert Rev Pharmacoecon Outcomes Res 2005; 5:593-601.

11. Isakbaeva ET, Musabaev E, Antil L, et al. Rotavirus disease in Uzbekistan: cost-effectiveness of a new vaccine. Vaccine 2007; 25:373-80.

12. UNICEF. The state of the world's children 2008. UNICEF, 2008. Available at: http://www.unicef.org/sowc08/statistics/tables.php. Accessed 22 February 2008.

13. McKee M, Healy J, Falkingham J. Health care in central Asia. Buckingham, United Kingdom: Open University Press, 2002.

14. Meimanaliev A-S, Ibraimova A, Elebesov B, Rechel B. Health care systems in transition: Kyrgyzstan. Copenhagen: World Health Organization Regional Office for Europe, on behalf of the European Observatory on Health Systems and Policies, 2005.

15. World Health Organization. WHO-UNICEF estimates of DTP3 coverage. Geneva: World Health Organization, 2007. Available at: http:// www.who.int/immunization_monitoring/en/globalsummary/timeseries/ tswucoveragedtp3.htm. Accessed 22 February 2008.

16. Griffiths U, Rheingans R, Walker D. Guidelines for estimating the economic burden of diarrhoeal disease with focus on assessing the costs of rotavirus diarrhea. Geneva: World Health Organization, 2005. Available at: http://www.who.int/vaccine_research/documents/ Eco_Burden_Diarrhoeal.pdf. Accessed 7 July 2008.

17. Interstate Statistical Committee of the Commonwealth of Independent States. Exchange rates of national currencies established of national (central) banks of the countries of the Commonwealth of Independent States in 2008. Interstate Statistical Committee of the CIS, 2008. Available at: http://www.cisstat.com/eng/index.htm. Accessed 25 May 2008.

18. World Health Organization. Choosing interventions that are cost-effective (WHO-CHOICE). Unit costs for patient services. Geneva: World Health Organization, 2000. Available at: http://www.who.int/ choice/costs/unit_costs/en/index.html. Accessed 7 July 2008.

19. International Monetary Fund. World economic outlook database. April 2008. Available at: http://www.imf.org/external/pubs/ft/weo/2008/01/ weodata/weoselgr.aspx. Accessed 7 July 2008.

20. Ruiz-Palacios GM, Perez-Schael I, Velazquez FR, et al. Safety and efficacy of an attenuated vaccine against severe rotavirus gastroenteritis. N Engl J Med 2006; 354:11-22.

21. Salinas B, Schael IP, Linhares AC, et al. Evaluation of safety, immunogenicity and efficacy of an attenuated rotavirus vaccine, RIX4414: a randomized, placebo-controlled trial in Latin American infants. Pediatr Infect Dis J 2005; 24:807-16.

22. World Health Organization. The world health report 2002-reducing risks, promoting healthy life. Geneva: World Health Organization, 2002:108.

23. Centers for Disease Control and Prevention. Postmarketing monitoring of intussusception after RotaTeq vaccination-United States, February 1, 2006-February 15, 2007. MMWR Morb Mortal Wkly Rep 2007; 56 : 218-22. 